\title{
Effects of omega-3 fatty acids and CoQ10 on gross morphology of intervertebral discs subjected to immobilization
} \author{
shwar Naheed ${ }^{6}$ \\ ${ }^{1}$ Mohterma Benazir Bhutto Shaheed Medical College, Mirpur, AJK \\ ${ }^{2}$ Department of Anatomy, Army Medical College, Rawalpindi \\ ${ }^{3}$ CMH Kharian Medical College, Kharian Cantt \\ ${ }^{4}$ Swat Medical College, Saidu Sharif, Swat. \\ ${ }^{5}$ Mohiuddin Islamic Medical College, Mirpur, AJK \\ ${ }^{6}$ Watim Medical and Dental College, Rawalpindi
}

Fareeha Mushtaq ${ }^{1}$, Abdullah Qamar ${ }^{2}$, Muhammad S. Abdullah ${ }^{3}$, Humaira Ali ${ }^{4}$, Maimoona Ali ${ }^{5}$, Ki-

\section{SUMMARY}

The aim of the study was to determine the effects of immobilization on the gross morphology of rats' intervertebral disc (IVD) and observe the ameliorating effects of Omega 3 fatty acids and Co-enzyme Q 10 (CoQ10). Forty Sprague Dawley rats weighing 250-300 $\mathrm{g}$ were procured from NIH Islamabad. The animals were randomly selected and were divided into four groups of 10 animals in each. Group-A rats served as control group. Each rat of Group B was disc immobilized by using an Illizarov-type apparatus, which was applied for 60 days. Group-C and -D rats after disc immobilization were administrated with Omega 3 fatty acids (260 mg/kg/day) and CoQ10 (150mg/ $\mathrm{kg} /$ day) through oral gavage respectively. Gross examination of IVD was done using the Thompson grading scale and the disc alterations were scored from grade 1 to 5 in increasing order of IVD alterations.

Gross examination of the sections of IVD's of the control group showed normal healthy morphology, falling in Thompson grade I degeneration. The frequency of disc alteration was statistically significant in disc-immobilized group B when compared to control group A (p-value $=0.000)$, group $C(p$-value $=0.000)$ and group $\mathrm{D}$ ( $\mathrm{p}$ value $=0.002$ ). Group $\mathrm{C}$ in which $\mathrm{n}-3$ fatty acid was given along with disc immobilization, showed significant improvement in disc degenerative changes. On comparison with group B, p-value\&lt;0.001 was statistically significant. In experimental Group D, where CoQ10 was given along with disc immobilization, the degenerative changes were significantly reduced as compared to Group B ( $\mathrm{p}=0.002)$. In this study, gross morphological changes were induced by immobilization in IVDs of the experimental rats and its reversal by omega 3 and CoQ10 was proven. Co-administration of Omega 3 and CoQ10 significantly minimized degenerative changes in IVDs induced by immobilization.

Key words: Intervertebral disc degeneration - Immobilization - Thompson Grade scoring - 
Nucleus pulposus - Annulus fibrosus - CoQ10 Omega 3 fatty acid

\section{INTRODUCTION}

An intervertebral disc (IVD) is a cartilaginous structure in which progressive degenerative and ageing changes appear earlier than any other connective tissue in the body. Clinically it is considered very important because there is strong association of disc degeneration with disability and devastating backache (Urban and Roberts, 2003). Back pain is a common community health problem and a leading cause of disability that causes suffering and distress to patients and their families. There is a decreased incidence of low back pain in people who are physically fit and active, whereas a sedentary lifestyle with reduced physical activity is related to an increased risk for low back pain (James et al., 1999). An IVD is composed of three components: in the centre nucleus pulposus (NP), gelatinous core which is surrounded by $15-20$ thick fibrous rings forming annulus fibrosus (AF), and the upper and lower end plates. Significant changes occur in these components that are indicative of disc degeneration. These include the destruction of extracellular matrix, the injury to the cells. Major morphological changes are observed in degenerated discs, where the annular lamellae become disorganized and irregular. In the NP, frequent cleft and fissure formation is seen (Buck Walter, 1995). An effective proteoglycan, Aggregan, is destroyed in degenerated discs, which lead to loss of hydration, and fragments of NP bulge into AF (Hayes et al., 2001).

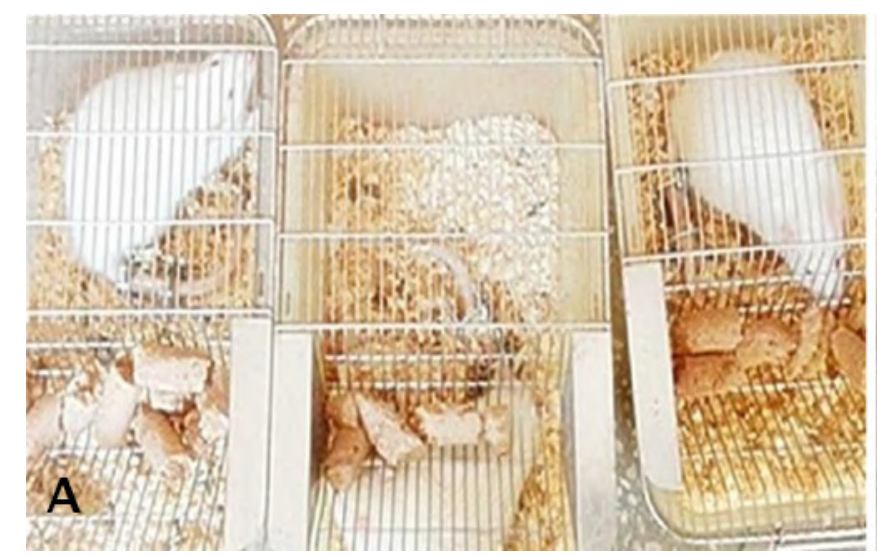

Nerlich studied that oxidative stress is a cellular state where raised levels of reactive oxygen species (ROS) may contribute to destruction of extracellular matrix and cell apoptosis, which eventually results in disc degeneration (Nerlich et al., 2007). Disc degeneration is a form of chronic inflammation which leads to an upregulation of pro-inflammatory markers that shift homeostasis towards the extracellular matrix degeneration, with successive breakdown of its components (Burke et al., 2002). We hypothesize that the potent antioxidant property of Co Q 10, as well as the ability of omega 3 fatty acids to inhibit a number of aspects of inflammation, present them as good therapeutic candidates to treat disc degeneration (Sohal and Forster, 2007) (Wall et al., 2010).

\section{MATERIALS AND METHODS}

Forty Sprague-Dawley rats 3 to 4 months of age, with an average weight of 250-300 grams, were used in the experiment and were kept in controlled environment of animal house of NIH, Islamabad. The study was carried out in the Department of Anatomy, Army Medical College Rawalpindi, in collaboration with National Institute of Health (NIH), Islamabad and Armed Force Institute of Pathology (AFIP), Rawalpindi. It was a laboratorybased experimental control trial that spanned for two months.

Rats were randomly divided into four groups (n $=10$ animals in each group). Animals were raised on NIH laboratory standard diet and water ad libitum for two months in separate cages (Fig. 1A). Rats in group A served as control and were given standard lab diet and water ad libitum for

Fig. 1.- A. Rats placed in separate cages after apparatus was applied. B. Illazrov apparatus applied to immobilize the rat tail segment. 
two months. Rats in group B were subjected to disc immobilization by using an Ilizarov-type apparatus (James et al., 1999). No medication was given to this group. They were given standard lab diet and water for two months. Rats in group $\mathrm{C}$ were subjected to disc immobilization using an Ilizarov type apparatus (Fig. 1B). They were administered omega 3FA through oral gavage at a dose of 260 $\mathrm{mg} / \mathrm{kg}$ body weight (Abdou et al., 2014). In group D, rats were subjected to disc immobilization and were given Co-enzyme Q10 through oral gavage at a dose of $150 \mathrm{mg} / \mathrm{kg} /$ day (Kwong et al., 2002). At the end of 60 days, the animals were sacrificed.

The whole discs with the vertebrae adjacent to the immobilized segments (Co8-9 and Co10) were removed and dissected. The removed part of the vertebral column was sectioned in a sagittal plane $5 \mathrm{~mm}$ from the mid-line. The lateral cut surface was washed briefly under running tap water while brushing the bone lightly with soft toothbrush to remove debris. The cleaned surface was photographed and observed under dissecting microscope (Fig. 2). For the macroscopic analysis of these disc alterations, the Thompson grading scale (Table 1) was used, which attributes a grade of 1 to 5 , in increasing order of intervertebral disc alterations (Thompson et al., 1990). A Sony digital camera (16 megapixel) was used through the ocular of the Olympus DP21 light microscope. The images were corrected and adjusted with respect to contrast, brightness, sharpness, and color balance by Photoscape software. IBM-SPSS version 21 was used for data analysis. Qualitative variables were presented by frequency and percentages. Chi square test was applied for comparison of qualitative variables.

\section{RESULTS}

Gross examination of IVD was done using the Thompson grading scale and the disc alterations were scored from grade 1 to 5 in increasing order of IVD alterations. On gross examination of specimens of Control Group A, intervertebral discs had soft central nucleus pulposus (NP) with well-

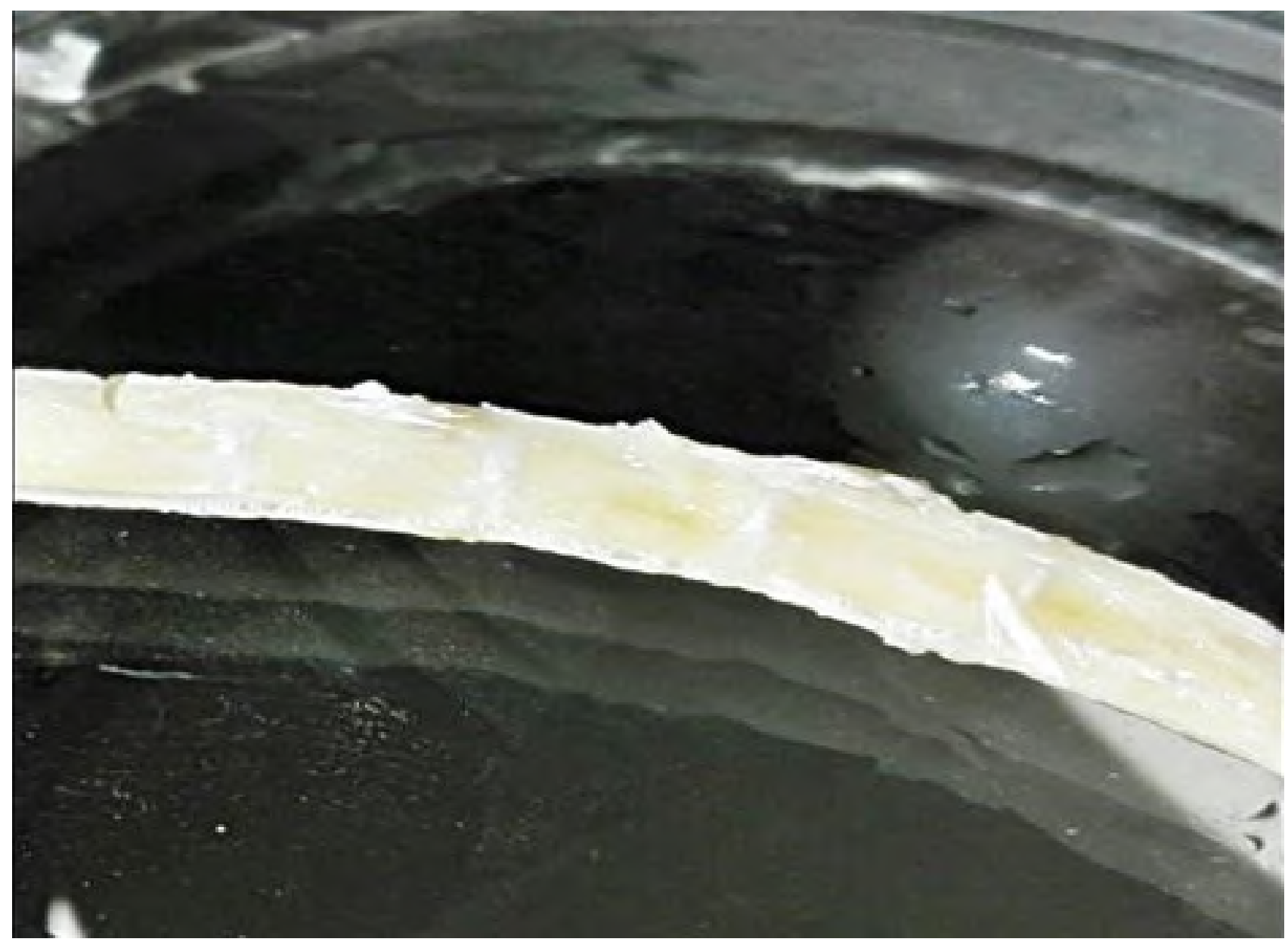

Fig. 2.- Rat tail under the dissecting microscope. 
organized annulus fibrosus (AF) lamellae. They did not have any fissures in NP or any disruption of AF (Table 1, Fig. 3, Bar chart 1). Ten (100\%) rats of the control group A showed Thompson grade I degeneration.

In disc-immobilized group $\mathrm{B}, 30 \%$ of the specimens showed Thompson III degeneration with loss of NP/AF distinction and fissures in $\mathrm{NP}$ and $50 \%$ of the specimens were lying in Thompson IV with fissures in NP and few points of focal sclerosis while $20 \%$ of the rats had flat discs and showed Thompson $\mathrm{V}$ degeneration. The frequency of disc alteration was statistically significant in disc-immobilized group B when compared to control group A (p-value=0.000), group C (p-value=0.000) and group D (p value $=0.002)($ Table 2, Fig. 4 and Bar chart 1$)$.

Group $\mathrm{C}$ in which n-3 fatty acid is given along with disc immobilization, $40 \%$ of the rats were lying in Thompson I grade, 50\% in Thompson II grade and $10 \%$ in Thompson III grade. On comparison with group $\mathrm{B}, \mathrm{p}$-value $<0.001$, and this was statistically significant. When compared with experimental group D with $\mathrm{p}$-value $=0.450$, the difference was statistically not significant (Table 2 and Bar chart 1).

Table 1. Thompson's macroscopic degeneration scale (Thompson et al., 1990).

\begin{tabular}{|l|l|}
\hline Thompson Grade & Description \\
\hline Thompson I & Nucleus pulposus of gelatinous appearance and annulus fibrosus with organized lamellae. \\
\hline Thompson II & $\begin{array}{l}\text { Nucleus pulposus with whitened fibrous tissue and mucinous material between the lamellae of the } \\
\text { annulus fibrosus, note small fissure in the NP. }\end{array}$ \\
\hline Thompson III & $\begin{array}{l}\text { Loss of AF/NP distinction, focal defects in end-plate, sees dehydration of nucleus pulposus and } \\
\text { longitudinal and vertical fissure. }\end{array}$ \\
\hline Thompson IV & Fissures in the nucleus pulposus and parallel to the end-plate, with presence of focal sclerosis at this point. \\
\hline Thompson V & Total sclerosis and flattening of the disc. \\
\hline
\end{tabular}

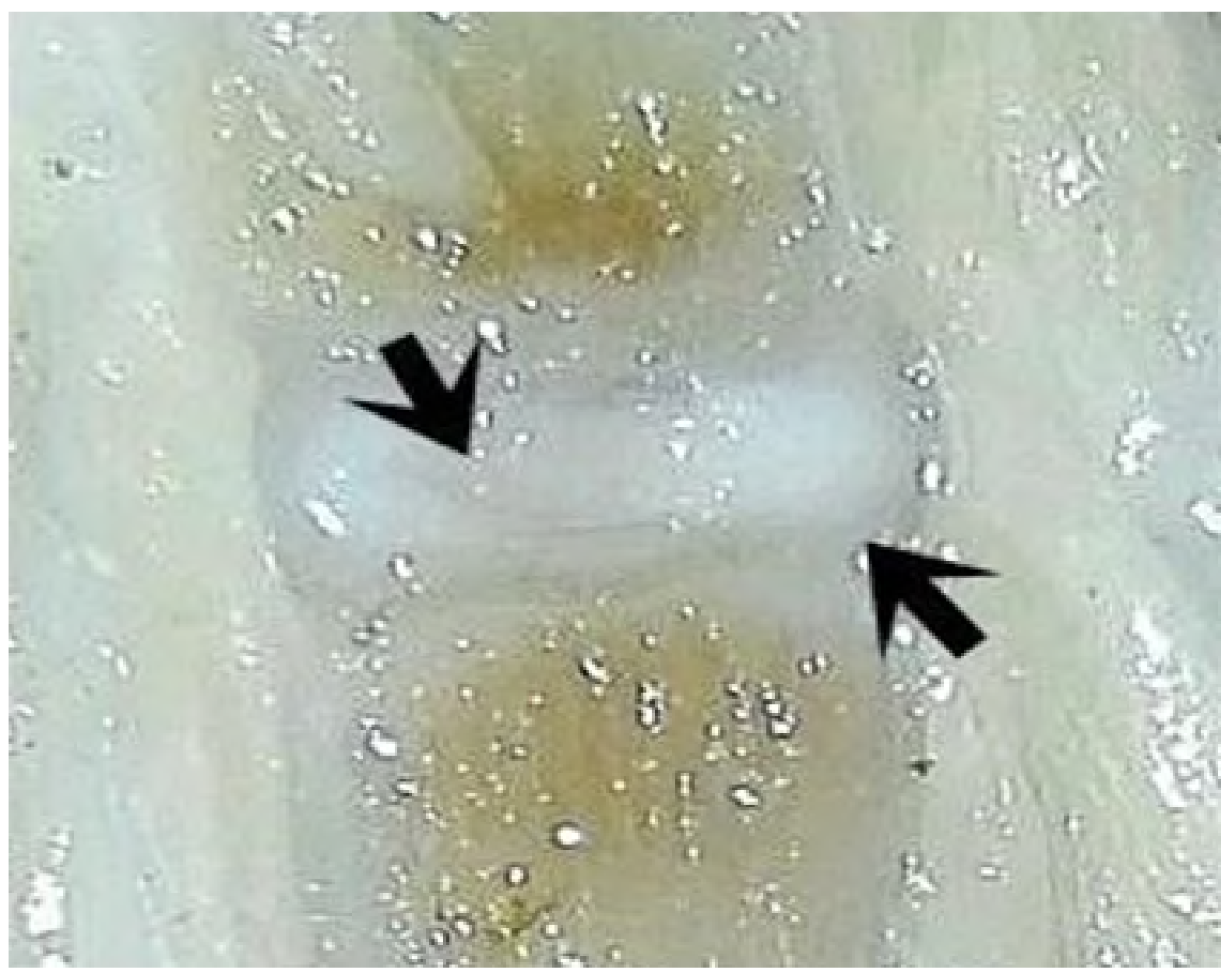

Fig. 3.- Normal healthy disc with central, gelatinous NP and well-organized AF in A6 rat of control group (Grade 1). 
Table 2. Comparison of Thompson's scoring and $\mathrm{p}$ values for macroscopic degeneration between the control Group A and the experimental Groups B, C and D.

\begin{tabular}{|c|c|c|c|c|c|c|c|c|c|c|}
\hline $\begin{array}{l}\text { Thompson's scale for mac- } \\
\text { roscopic degeneration }\end{array}$ & $\begin{array}{l}\text { Group A } \\
(n=10)\end{array}$ & $\begin{array}{l}\text { Group B } \\
(n=10)\end{array}$ & $\begin{array}{l}\text { Group C } \\
(n=10)\end{array}$ & $\begin{array}{l}\text { Group D } \\
(\mathbf{n}=10)\end{array}$ & $\begin{array}{l}\text { Group } \\
\text { A/B }\end{array}$ & $\begin{array}{l}\text { Group } \\
\text { A/C }\end{array}$ & $\begin{array}{l}\text { Group } \\
\text { A/D }\end{array}$ & $\begin{array}{l}\text { Group } \\
\text { B/C }\end{array}$ & $\begin{array}{l}\text { Group } \\
\text { B/D }\end{array}$ & $\begin{array}{l}\text { Group } \\
\text { C/D }\end{array}$ \\
\hline Thompson I & $10(0 \%)$ & $0(0 \%)$ & $4(40 \%)$ & $2(20 \%)$ & \multirow[t]{5}{*}{$0.000^{*}$} & \multirow[t]{5}{*}{$0.011^{*}$} & \multirow[t]{5}{*}{$0.001^{*}$} & \multirow[t]{5}{*}{$0.000 *$} & \multirow[t]{5}{*}{$0.002^{*}$} & \multirow[t]{5}{*}{0.450} \\
\hline Thompson II & $0(0 \%)$ & $0(0 \%)$ & $5(50 \%)$ & $5(50 \%)$ & & & & & & \\
\hline Thompson III & $0(0 \%)$ & $3(30 \%)$ & $1(10 \%)$ & $3(30 \%)$ & & & & & & \\
\hline Thompson IV & $0(0 \%)$ & $5(50 \%)$ & $0(10 \%)$ & $0(0 \%)$ & & & & & & \\
\hline Thompson V & $0(0 \%)$ & $2(20 \%)$ & $0(0 \%)$ & $0(0 \%)$ & & & & & & \\
\hline
\end{tabular}
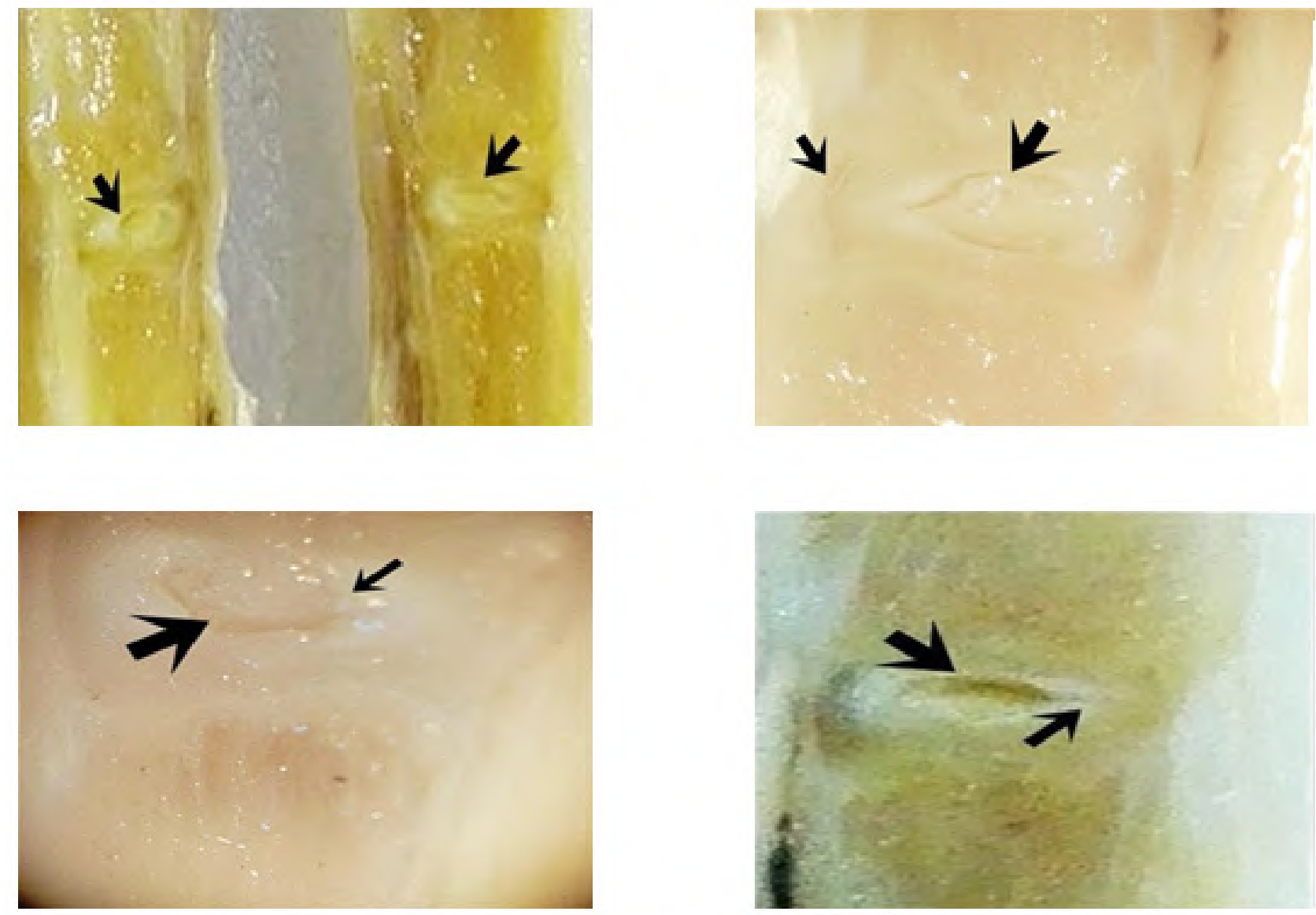

Fig. 4.- Different grades of gross morphological changes observed in intervertebral discs of rats of group B under dissecting microscope.

Whereas in experimental Group D, where CoQ10 is given along with disc immobilization, $20 \%$ of specimens showed Thompson I disc alterations, 50\% showed Thompson II grade and 30\% had Thompson III disc degeneration. On intergroup comparison it was found to be statistically significant with Group B ( $\mathrm{p}=0.002)$ (Table 2 and Bar chart 1).

\section{DISCUSSION}

This study indicated that immobilization induced in rats resulted in IVD degeneration. The causes for IVD degeneration are multifactorial and risk factors include heritability, ageing, rapid increase in weight, obesity, and physical activity levels. Effects of immobilization on IVD have been researched comprehensively; the main aim of this study was to appraise the beneficial effects 
of nutraceuticals having anti-inflammatory and antioxidant properties in treating spinal pathologies.

Gross morphology of intervertebral discs was observed and graded with the help of two pathologists using Thompson's scale. All the animals in control group A showed healthy discs with no signs of degeneration. Gross morphological changes were significant and the severity (score) of disc degeneration was found to be significantly more in the disc-immobilized group $\mathrm{B}$, and this validated the findings of the previous researchers, who established the adverse effects of prolong immobilization on disc morphology (Scholten et al., 2014; Che et al., 2018). Pro-inflammatory cytokines including interleukin-1 $\beta$, interleukin-6, interleukin-8, interleukin-10, bFGF (basic fibroblast growth factor), phospholipase A2, PGE2 (prostaglandin E2) and TNF- $\alpha$ are released because of the destruction of ECM in IVD (Podichetty, 2007). It is established that these mechanisms lead to densification and disruption of the fibers constituting the annulus fibrosus (AF), progressive loss of distinction between annulus and nucleus, the formation of chondrocyte clusters in the deep part of the disc, the appearance of horizontal or vertical fissures in the disc, anterior and posterior herniation (with total or partial rupture of the fibers of $A F$ ) and flattening of disc (Baptista et al., 2015). Decreased cytokine-mediated ECM degeneration can be a more potent approach, since it interfered with an earlier phase in the pathway of IVD degeneration. The degenerative changes observed on gross morphology were reduced in frequency in group where omega 3 fatty acids were used. This is due to the fact that omega 3 fatty acids, when consumed in sufficient quantities, result in decreased leukocyte chemotaxis and decreased pro-inflammatory cytokines, and decreased adhesion molecule expression (Maroon and Bost, 2006), thus reducing damage to the intervertebral disc morphology. These results are in agreement

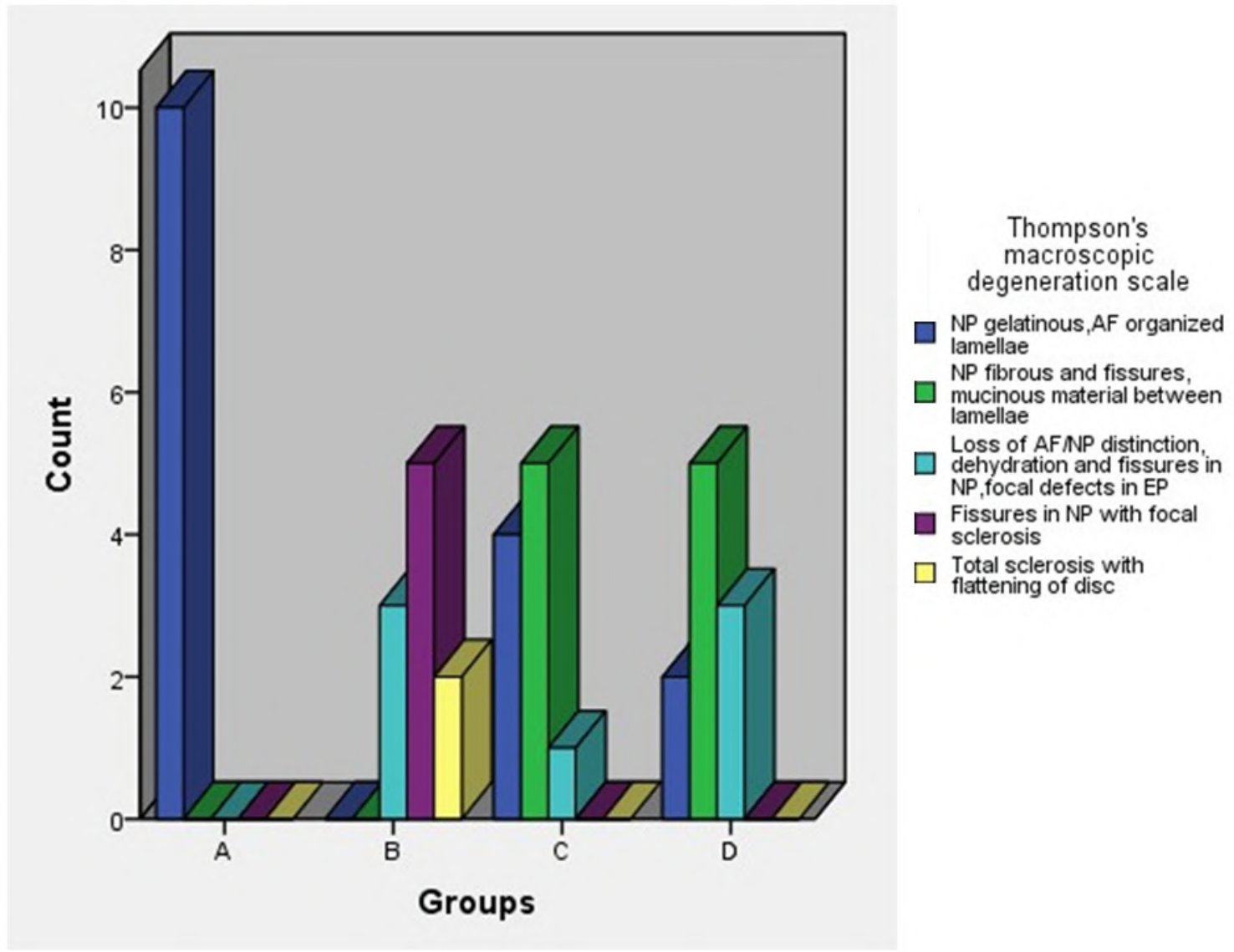

Bar chart 1. Clustered bar chart showing count of intervertebral discs (IVD) with scoring of macroscopic degeneration (Thompson's scale) among the control group A, disc immobilized group B, disc immobilized+Omg3 administrated group C and disc immobilized+CoQ10 administrated group D. 
with the findings of Calder (2006). In recent years, numerous studies have demonstrated that oxidative stress plays an important role in the initiation and progression of disc degeneration (Suzuki et al., 2015).These reports led us to see an anti-oxidative therapy for alleviating oxidative stress on cells that may allow a slow but controlled regeneration of disc. Co Q10 is widely consumed by humans as dietary supplement and acts as a quencher of ROS. This motivated us to study the long term effects of Co Q10 on IVD degenerative process. The incidence of degenerative morphological changes was reduced in group D, given Co Q10, as compared to group B. These results are in accordance with those previously reported studies that have shown substantial reduction in oxidative stress and improvement in long-term degenerative diseases with oral Co Q10 supplementation (Sanoobar et al., 2013; Santoro, 2020). This is in agreement with a study that argues that antioxidant therapy aids in stabilizing blood vessels and reduce oxidative damage caused from degeneration within the IVD (Zhang et al., 2020).

\section{CONCLUSION}

Immobilization induced the gross morphological changes in the intervertebral discs of the experimental rats by increasing inflammation and oxidative stress. Co-administration of omega 3 fatty acids and enzyme CoQ10 minimized the immobilization-induced degeneration and improved the gross morphology of IVD, scored by using Thomson Grading Scale.

\section{REFERENCES}

ABDOU HM, HASSAN MA (2014) Protective role of omega 3 polyunsaturated fatty acid against lead acetate-induced toxicity in liver and kidney of female rats. BioMed Res, 2014: 435857.

BAPTISTA JS, FONTES RB DE V, LIBERTI EA (2015) Aging and degeneration of the intervertebral disc: Review of basic science. Coluna/ Columna, 14(2): 144-148.

BUCKWALTER JA (1995) Aging and degeneration of the human intervertebral disc. Spine, 20(11): 1307-1314.

BURKE JG, WATSON RW, MCCORMACK D, DOWLING FE, WALSH MG, FITZPATRICK JM (2002) Intervertebral discs which cause low back pain secrete high levels of proinflammatory mediators. J Bone Joint Surg Br, 84(2): 196-201.

CHE YJ, LI HT, LIANG T, CHEN X, GUO JB, JIANG HY, LUO ZP, YANG HL (2018) Intervertebral disc degeneration induced by long-segment in-situ immobilization: a macro, micro, and nanoscale analysis. $B M C$ Musculoskelet Disord, 19(1): 1-10.
FRYMOYER JW, POPE MH, CLEMENTS JH, WILDER DG, MACPHERSON B, ASHIKAGA T (1983) Risk factors in low-back pain. An epidemiological survey. JBJS, 65(2): 213-218.

JAMES CI, PETER LM, IAN AFS, DAVID DA, MAURO A (1999) Compression-induced changes in intervertebral disc properties in a rat tail model. Spine, 24(10): 996-1002.

KWONG LK, KAMZALOV S, REBRIN I, BAYNE ACV, JANA CK, MORRIS P (2002) Effects of coenzyme Q10 administration on its tissue concentrations, mitochondrial oxidant generation, and oxidative stress in the rat. Free Radical Biol Med, 33(5): 627-638.

MARCHAND F, AHMED AM (1990) Investigation of the laminate structure of lumbar disc anulus fibrosus. Spine, 15(5): 402-410.

MAROON JC, BOST JW (2006) Omega-3 fatty acids (fish oil) as an anti-inflammatory: an alternative to nonsteroidal anti-inflammatory drugs for discogenic pain. Surg Neurol, 65(4): 326-331.

NERLICH AG, BACHMEIER BE, SCHLEICHER E, ROHRBACH H, PAESOLD G, BOOS N (2007) Immunomorphological analysis of RAGE receptor expression and $\mathrm{NF}-\mathrm{kB}$ activation in tissue samples from normal and degenerated intervertebral discs of various ages. Ann New York Acad Sci, 1096(1): 239-248.

PODICHETTY VK (2007) The aging spine: the role of inflammatory mediators in intervertebral disc degeneration. Cell Mol Biol, 53(5): 4-18.

SANOOBAR M, EGHTESADI S, AZIMI A, KHALILI M, JAZAYERI S, REZA GOHARI M (2013) Coenzyme Q10 supplementation reduces oxidative stress and increases antioxidant enzyme activity in patients with relapsing-remitting multiple sclerosis. Int J Neurosci, 123(11): 776782.

SANTORO MM (2020) The antioxidant role of non-mitochondrial CoQ10: mystery solved! Cell Metab, 31(1): 13-15.

SCHOLTEN I, CUSTERS IM, MOOLENAAR LM, FLIERMAN PA, COX T, GIANOTTEN J, HOMPES PGA, VAN DER VEEN F, MOL BW (2014) Longterm follow up of couples initially randomized between immobilization and immediate mobilization subsequent to IUI. Reprod Biomed Online, 29(1): 125-130.

SOHAL RS, FORSTER MJ (2007) Coenzyme Q, oxidative stress and aging. Mitochondrion, 7 (Suppl): S103-S111. https://doi.org/10.1016/j. mito.2007.03.006

SUZUKI S, FUJITA N, HOSOGANE N, WATANABE K, ISHII K, TOYAMA Y, TAKUBO K, HORIUCHI K, MIYAMOTO T, NAKAMURA M, MATSUMOTO M (2015) Excessive reactive oxygen species are therapeutic targets for intervertebral disc degeneration. Arthritis Res Ther, 17: 316

THOMPSON JP, PEARCE RH, SCHECHTER MT, ADAMS ME, TSANG IK, BISHOP PB (1990) Preliminary evaluation of a scheme for grading the gross morphology of the human intervertebral disc. Spine, 15(5): 411-415.

URBAN JP, ROBERTS S (2003) Arthritis research \& therapy. Arthritis Res Ther, 5(3): 120-130.

WALL R, ROSS RP, FITZGERALD GF, STANTON C (2010) Fatty acids from fish: the anti-inflammatory potential of long-chain omega-3 fatty acids. Nutr Rev, 68(5): 280-289.

ZHANG Q, LI J, LI Y, CHE H, CHEN Y, DONG J, XIAN CJ, MIAO D, WANG L, REN Y (2020) Bmi deficiency causes oxidative stress and intervertebral disc degeneration which can be alleviated by antioxidant treatment. J Cell Mol Med, 24(16): 8950-8961. 